\title{
Comparing the Efficacy and Safety of Treating Chronic Hepatitis B Infection during Pregnancy with Lamivudine, Telbivudine, and Tenofovir: A Meta-analysis
}

\author{
Shahnaz Sali ${ }^{1}$, Mohammad Darvishi*2, Mojtaba GhasemiAdl ${ }^{3}$, Meisam Akhlaghdoust ${ }^{4}$, \\ Azin Mirzazadeh ${ }^{5}$, Somayeh Elikaei Behjati ${ }^{6}$, Hossein Sheikh-Zeinolabedini ${ }^{6}$, \\ Shervin Shokouhi ${ }^{1}$ and Soheil Tavakolpour*1,3
}

\begin{abstract}
${ }^{1}$ Infectious Diseases and Tropical Medicine Research Center, Shahid Beheshti University of Medical Sciences, Tehran, Iran; ${ }^{2}$ Department of Aerospace and Subaquatic Medicine, Infectious Diseases and Tropical Medicine Research Center (IDTMRC), AJA University of Medical Sciences, Tehran, Iran; ${ }^{3}$ Pharmaceutical Sciences Research Center, Tehran University of Medical Sciences, Tehran, Iran; ${ }^{4}$ Pars Advanced and Minimally Invasive Medical Manners Research Center, Pars Hospital, Iran University of Medical Sciences, Tehran, Iran; ${ }^{5}$ Joint Bioinformatics Graduate Program, University of Arkansas Little Rock and University of Arkansas for Medical Sciences, Little Rock, AR, USA; ${ }^{6}$ The Genetics Department at Islamic Azad University, Science and Research Branch,
\end{abstract}

Tehran, Iran

\begin{abstract}
Background and Aims: The perinatal transmission of hepatitis $B$ virus (HBV) remains an important global health problem. Here, a systematic review and meta-analysis were conducted to evaluate the evidence regarding the efficacy and maternal/fetal safety of treating pregnant women with lamivudine, telbivudine (LdT), and tenofovir (TDF). Methods: A PubMed and Scopus search resulted in 1,076 records, which were reduced to 36 , containing 7,717 pregnant women with chronic HBV infection and 7467 infants meeting the inclusion criteria. The latest search was in August 2019. Results: Treatment with LdT, but not lamivudine and TDF, could significantly reduce the hepatitis $B$ virus surface antigen-positive rate (odds ratio $(O R)=0.37$ ) in infants; it also led to higher rates of hepatitis $B$ e antigen loss $(\mathrm{OR}=12.14)$, hepatitis $\mathrm{B}$ e antigen seroconversion $(\mathrm{OR}=8.93)$, and alanine aminotransferase normalization in mothers $(O R=1.49)$. Each of these treatments was able to significantly reduce HBV DNA positivity at birth (total OR = 0.19 ) and mother-to-child-transmission of HBV (total OR = $0.15)$, and to cause higher rates of HBV DNA suppression in mothers (total OR $=25.53$ ). However, nucleos(t)ide analogues might also be involved in creatine kinase elevation (total $\mathrm{OR}=7.48$ ). In contrast, no significant association was found between nucleos(t)ide analogue therapy and preterm/premature births, congenital malformation, low birth weight, and abortion or fetal/infant death. The results sug-
\end{abstract}

Keywords: Hepatitis B virus; Antiviral therapy; Tenofovir; Telbivudine; Lamivudine; Nucleos(t)ide analogues; Pregnancy.

Abbreviations: $\mathrm{CHB}$, chronic HBV infection; $\mathrm{CI}$, confidence interval; $\mathrm{CK}$, creatine kinase; HBeAg, hepatitis $B$ e antigen; HBsAg, hepatitis $B$ virus surface antigen; HBV, hepatitis B virus; LAM, lamivudine; LdT, telbivudine; MTCT, mother-to-childtransmission; NA, nucleos(t)ide analogue; TDF, tenofovir.

Received: 7 June 2019; Revised: 13 August 2019; Accepted: 19 August 2019 *Correspondence to: Soheil Tavakolpour, Infectious Diseases and Tropical Medicine Research Center, Shahid Beheshti University of Medical Sciences, Tehran 1983963113, Iran. Tel/Fax: +98-2122267157, E-mail: Soheil.tavakolpour@gmail.com; Mohammad Darvishi, Department of Aerospace and Subaquatic Medicine, Infectious Diseases and Tropical Medicine Research Center (IDTMRC), AJA University of Medical Sciences, Tehran, Iran. E-mail: darvishi1349@gmail.com gested LdT's high capability of preventing mother-to-childtransmission. However, TDF failed to show significant associations to a reduced risk of mother-to-child-transmission, probably due to the low number of patients included. Conclusions: Although using either lamivudine, LdT, or TDF could lead to more favorable maternal/fetal outcomes, LdT seemed to show more potential in resolving certain infant- and maternal-related outcomes. More studies on the safety profile of such treatments are required.

Citation of this article: Sali S, Darvishi M, GhasemiAdl M, Akhlaghdoust M, Mirzazadeh A, Behjati SE, et al. Comparing the efficacy and safety of treating chronic hepatitis B infection during pregnancy with lamivudine, telbivudine, and tenofovir: A meta-analysis. J Clin Transl Hepatol 2019;7(3):197-212. doi: 10.14218/JCTH.2019.00021.

\section{Introduction}

Approximately 240 million people are chronically infected with hepatitis B virus (HBV), which has a high rate of mortality annually. ${ }^{1}$ During recent decades, the epidemiology of HBV infection had decreased, due to the impact of universal infant vaccination programs. HBV vaccination is an effective and safe approach, given on day 0 and at the end of 1 month and 6 months. ${ }^{2}$ However, this method is ineffective for patients already infected with HBV.

HBV can be acquired by contaminated blood product exposure, sexual activity, and perinatal transmission. Perinatal transmission, or mother-to-child transmission (MTCT), remains a critical infection route in hepatitis $B$-endemic countries. Regardless of the fact that pegylated-interferon alpha-2a can lead to high rates of hepatitis $B$ virus surface antigen (HBsAg) loss, ${ }^{3}$ nucleos(t)ide analogues (NAs), including lamivudine (LAM), telbivudine (LdT), entecavir, adefovir and tenofovir (TDF), are unable to eradicate this chronic infection. However, they seem to be able to decrease the risk of MTCT. Without prophylaxis, in mothers who are positive for both HBsAg and hepatitis B e antigen (HBeAg), the risk for transmission to the baby is high. ${ }^{4}$ In a considerable 
number of newborn infants from mothers with chronic HBV infection (CHB) infection, HBsAg and/or HBV DNA detection is positive, which may either take months to clear after birth or even become chronic. ${ }^{5-9}$

The majority of data regarding the safety and efficacy of anti-HBV therapies have been derived from studies conducted on human immunodeficiency virus (HIV)-positive mothers. ${ }^{10,11}$ However, during recent years, an increasing number of studies have focused on assessing the safety and efficacy of antiviral agents in pregnancy for HBV-infected women and their infants. Because of a wide number of studies that have reported the efficacy and safety of antiviral therapy via different types of approved NAs, and their widely different results, it is important to conduct an up-to-date analysis of these studies. Thus, we conducted a systematical review and meta-analysis to reveal the most potent and safest drugs, as well as to evaluate the risks and benefits associated with NAs therapy in pregnant women with CHB.

Although other comprehensive systematic reviews and meta-analyses have been conducted, the results needed to be updated and to cover various different aspects of NAs therapy during pregnancy. For example, Brown et al. ${ }^{12}$ performed a systematic review and meta-analysis comparing the effect of oral HBV therapy on different infant and maternal outcomes. However, that study was carried out years ago and may need to be updated, based on recently published studies. A more recent attempt by Hyun et al. ${ }^{13}$ conducted a meta-analysis containing 10 studies ( 733 women) on the efficacy and safety of TDF. Those investigators found it a safe and tolerable drug for both the mother and fetus. Comparing the efficacy and safety of LAM, LdT, and TDF with the latest reported studies may be beneficial in revising current findings on the management of $\mathrm{HBV}$-infected mothers during their pregnancies.

\section{Methods}

\section{Publication search}

A systematic literature search was conducted for all published articles associated with NAs therapy for CHB during pregnancy, using the PubMed and Scopus databases, with no limitation period. The last search update was on August 1, 2019. Selected keywords covered all studies associated with LAM, LdT, and TDF therapies for CHB during pregnancy. The keywords employed were ((Tenofovir) OR (Telbivudine) OR (Adefovir) OR (Entecavir) OR (Lamivudine) OR (Nucleoside analogues) OR (Nucleotide analogues) OR (Nucleos(t)ide analogues)) AND ((Hepatitis B virus) OR (HBV)) AND ((Pregnancy) OR (Pregnant) OR (Intrauterine transmission) OR (Perinatal transmission) OR (Utero transmission) OR (Vertical transmission)). The references for the selected articles were also checked for any articles missed.

\section{Selection criteria}

Among the studies found, only controlled or comparative studies that enrolled pregnant women diagnosed with $\mathrm{CHB}$ infection (a persistence of HBsAg for more than 6 months), who received LAM, LdT, or TDF were considered for analysis. As the current recommendation of NAs treatment for MTCT had been suggested to be initiated from week 24 of pregnancy, studies that contained only patients treated before week 24 were excluded. The studies needed to include essential information, such as the type of treatment(s) and recorded outcomes during the pregnancy and/or delivery, as well as infant outcomes. All the studies included had to compare the results with control groups, which could be defined as pregnant women who did not receive any type of oral HBV therapy during the pregnancy. However, their infants may have been treated with hepatitis $B$ immune globulin and/ or vaccine. Only studies in English were considered. Moreover, studies of patients coinfected with hepatitis C, hepatitis $D$, or human immunodeficiency virus were excluded, to minimize the effects of other diseases in the outcomes of treatments. In addition to the original articles, review studies and meta-analyses were searched for probable missing reports and studies.

\section{Data extraction}

Data extraction was performed from each article by two authors, independently. All the extracted data, including patient characteristics, treatment protocols, as well as maternal and infant outcomes, were carefully reviewed and categorized before discussion. The final extended data were rechecked with caution, compared, and inconsistencies resolved by referring to the full text of the articles.

\section{Outcomes}

Both maternal and infant outcomes were considered and analyzed. Infant outcomes, including the risk of MTCT, HBV DNA and HBsAg positivity at birth and at the age of 6-12 months, congenital malformation, low birth weight rate, premature/preterm birth rate, abortion rate, and infant/ fetus fetal rate were considered. MTCT was defined by HBsAg seropositivity and/or HBV DNA positivity at 6-12 months. Moreover, maternal outcomes were also taken into account, including HBV DNA suppression, alanine aminotransferase normalization, $\mathrm{HBeAg}$ loss/seroconversion, postpartum hemorrhage rate, and elevated creatine kinase (CK).

\section{Statistical analysis}

Statistical analyses were carried out using Review Manager statistical software, version 5.3. Dichotomous data were expressed as odds ratio (OR) and 95\% confidence intervals (CIs). Mantel-Haenszel was used. Otherwise, the meta-analysis was conducted using a fixed-effect model. ${ }^{14}$ Specifically, the analysis was performed with the use of a random-effects model (Mantel-Haenszel) after exploring for causes of heterogeneity or the fixed-effects models. Cochran $\mathrm{Q}$ test and the $I^{2}$ statistic were used for examining heterogeneity among studies and were considered significant if $p<0.10$ or $I^{2}>50 \%$. When significant heterogeneity in the results was observed, the random effect model was employed. However, in homogeneous conditions, the fixed-effect model was used. During the entire study, a $p$-value of $<0.05$ was considered as statistically significant for all outcomes.

\section{Results}

The initial search resulted in 1,076 records. Before starting the primary screening, duplicate records, and non-English articles were identified and excluded $(n=269)$. Checking titles of the articles led to the omission of 529 records. The remaining studies $(n=278)$ were evaluated by reviewing 
their abstracts. As a result, 173 studies were identified as nonrelevant records. Finally, the full text of 105 studies was checked to select those matching the inclusion criteria. Seventy articles were excluded, due to different reasons (lack of original data, not containing control group, insufficient data, acute HBV, combination therapy, treatment initiation in the first trimester, and case report), while one new study was included which had not appeared among the original search results. Eventually, 36 studies were included for meta-analysis. The study selection process and reasons for exclusions are presented in Fig. 1.

\section{Studies' selection and characteristics}

Thirty-six studies, containing 7,717 pregnant women $(4,468$ treated; 3,249 untreated) with $\mathrm{CHB}$ and 7,467 infants $(4,317$ from treated mothers; 3,150 from untreated mothers), were included. From these studies, there were 15 groups treated with LAM, 17 groups treated with LdT, ${ }^{4,6-9,15-26}$ and 12 groups treated with TDF. ${ }^{16,24,26-35}$ Some of them covered more than one NA $(n=7){ }^{7,15,16,24,26,28,31}$ Contrary to relatively older studies, the majority of recent studies did not cover LAM. In all studies for the group under treatment, antiviral therapy was initiated in the second or third trimester, while discontinuance occurred at different times. All the studies presented original data associated with the control group, except for one, where the control group was taken from documented patient data in the literature. ${ }^{36}$ Table 1 summarizes the characteristics of the studies.

\section{Infant outcomes}

Comparison of antiviral therapy with no treatment: Results adapted from 25 studies in the analysis revealed that NA (LAM, LdT, and TDF) therapies could significantly reduce the rate of $\mathrm{HBsAg}$ positivity at birth for infants born from CHB mothers (OR [95\% CIs] $=0.50[0.38,0.67] ; I^{2}=$ $61 \%$; $p$-value $<0.00001$ ) (Fig. 2 ). As the results of treating CHB-positive pregnant women with these drugs, the risk of birth of an infant with positive HBV DNA was also reduced significantly (OR $\left[95 \%\right.$ CIs] $=0.19[0.10,0.36], I^{2}=84 \%$, $p$-value $<0.00001$ ) (Fig. 3). The rate of MTCT for any separated drug was extractable in almost all studies included. Reports were analyzed from a total of 3,629 newborn infants from $\mathrm{CHB}$ mothers and 3,245 controls, who had received hepatitis $B$ immune globulin and vaccine, and also were followed for more than 6 months. Results from the 36 studies revealed that starting antiviral therapy in the second or third trimester could significantly protect infants from $\mathrm{CHB}$ (OR [95\% CIs] $=0.15[0.11,0.19], I^{2}=12 \%, p$-value $<0.00001$ ) (Fig. 4).

Following analysis of the risk of congenital malformation in a total of 1,954 born babies from CHB mothers and 2,194 controls, no statistical difference was obtained. However, those who were exposed to NA therapy seemed to be more
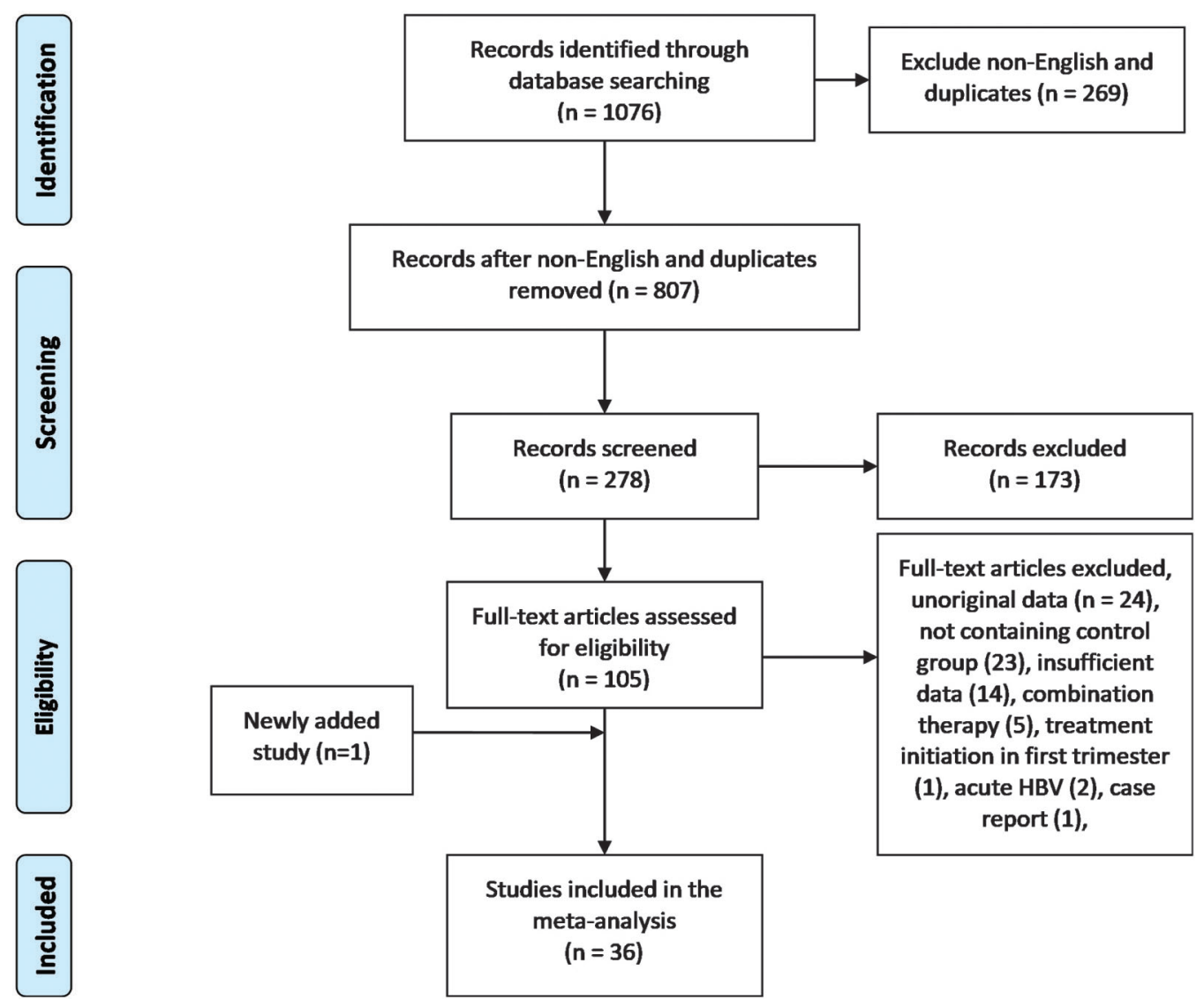

Fig. 1. The study selection process. 
Sali S. et al: Treating chronic HBV during pregnancy

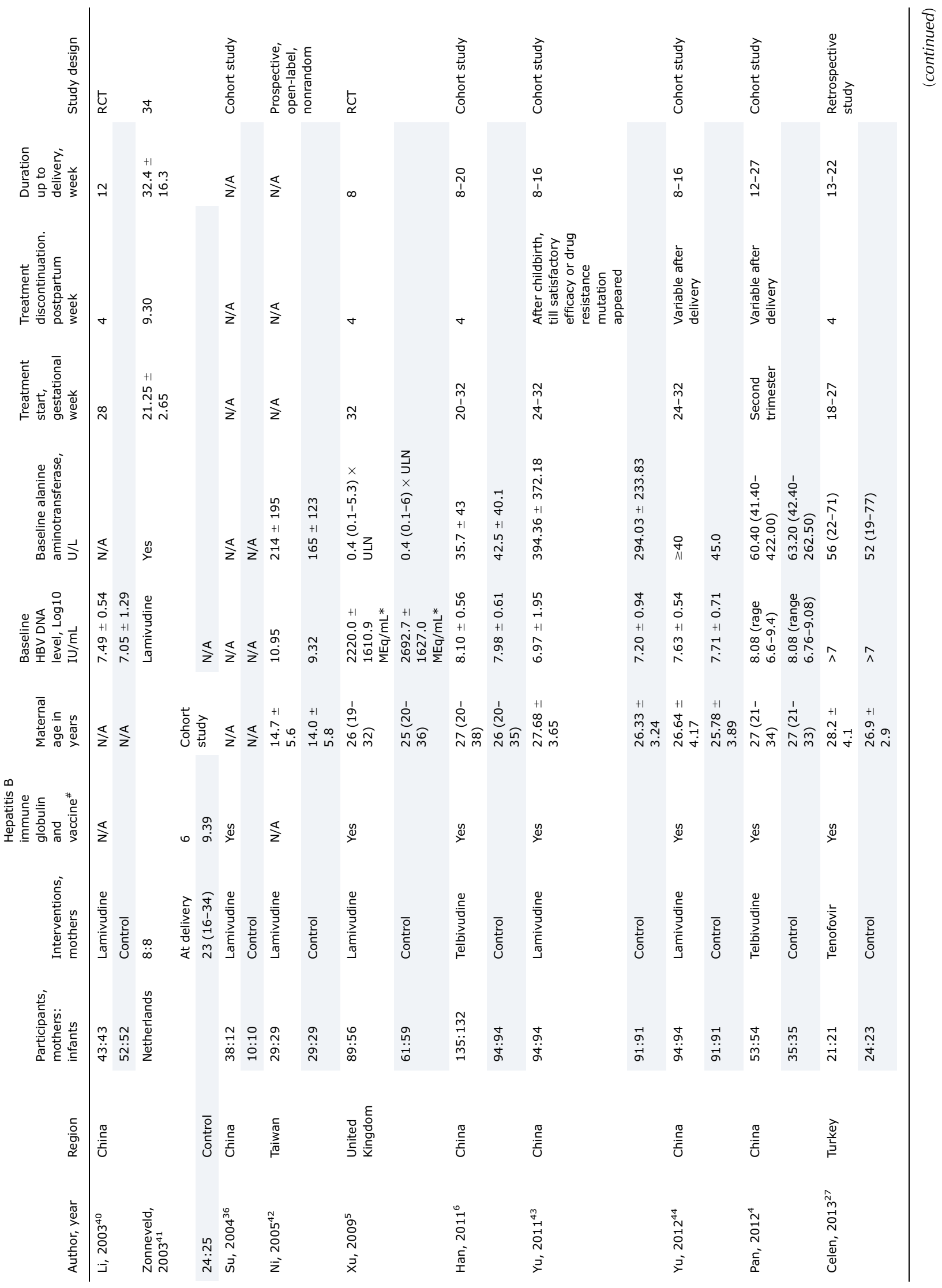


Sali S. et al: Treating chronic HBV during pregnancy

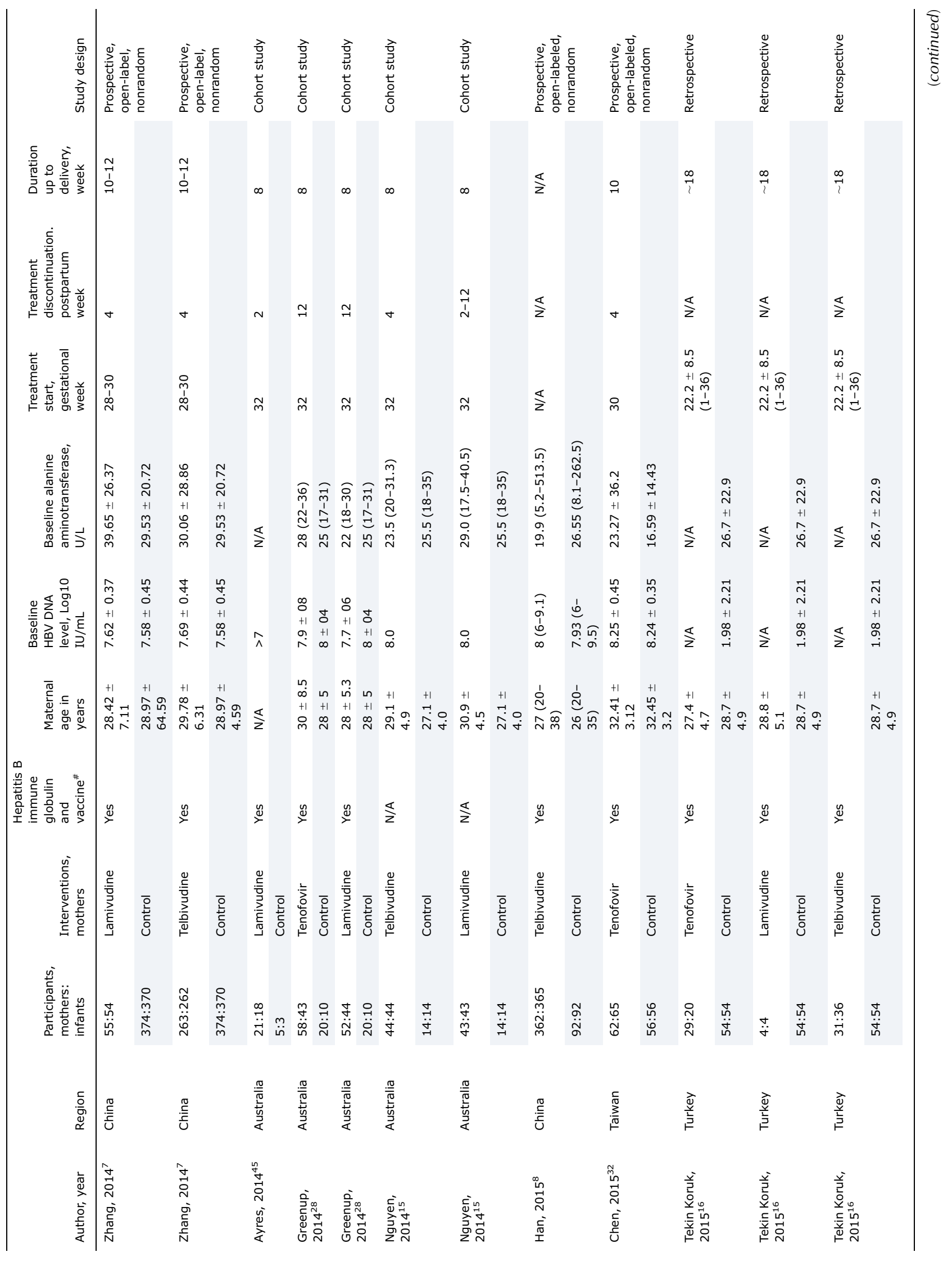


Sali S. et al: Treating chronic HBV during pregnancy




Sali S. et al: Treating chronic HBV during pregnancy

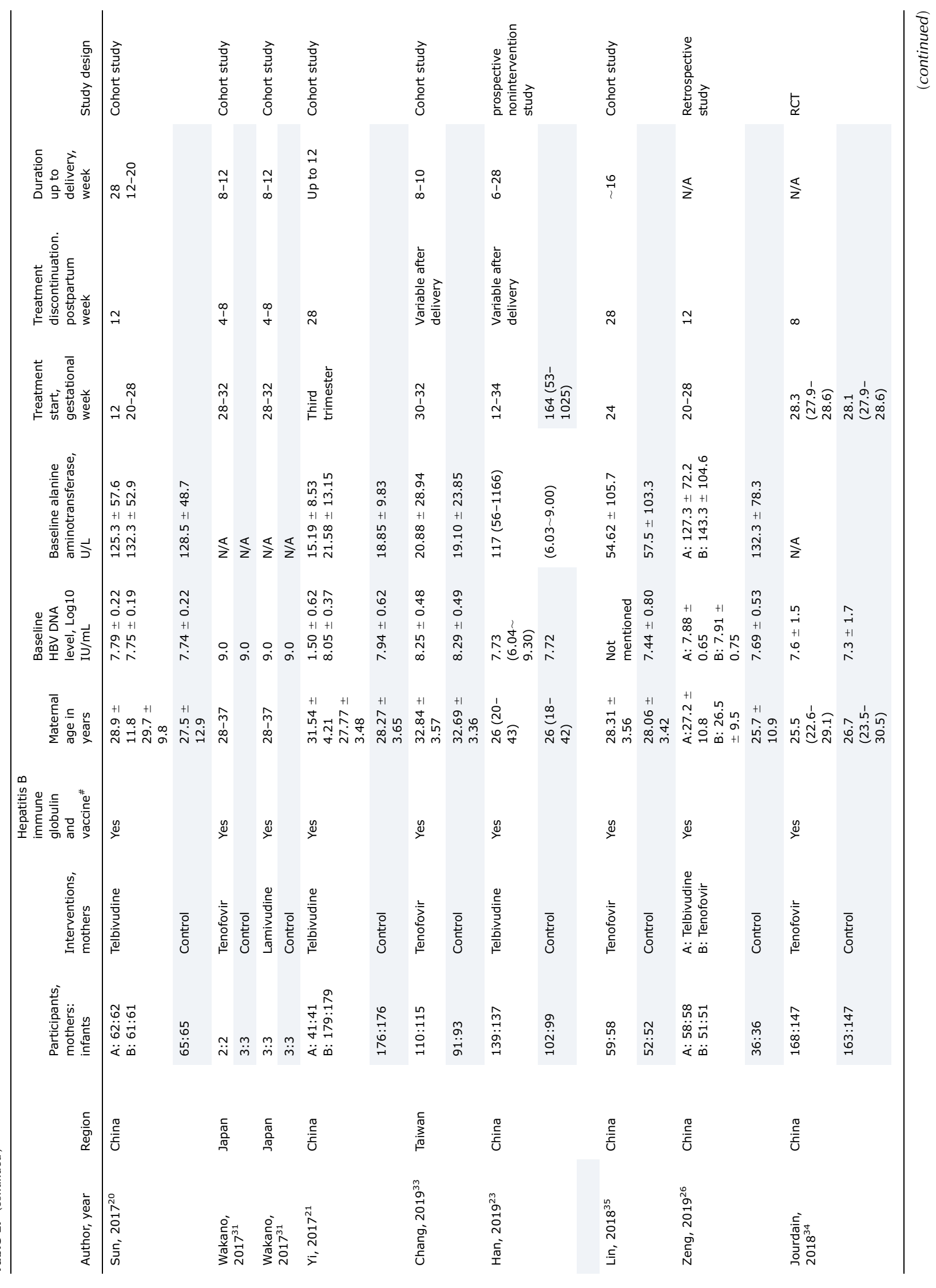



CIs $]=1.55[0.80,3.00], I^{2}=0 \%, p$-value $\left.=0.19\right)$. Regarding low birth weight, nine studies were available, which did not show a significant difference among the treated and untreated groups (OR [95\% CIs] $=0.95[0.57,1.61], I^{2}=$ $0 \%, p$-value $=0.86)$. In order to evaluate the risk of NAs therapy threatening the life of a fetus/infant, abortion and fetal/infant death were analyzed separately. The results suggest a probable protective role of NAs therapy for each of these factors, but they were not significantly different among the treated and untreated patients (abortion: OR $[95 \%$ CIs $]=0.47[0.11,1.92], I^{2}=31 \%, p$-value $=0.29$; fetal/infant death: OR [95\% CIs] $=0.90[0.54,1.50], I^{2}=$ $10 \%, p$-value $=0.44)$.

There were 15 studies that compared premature/preterm birth rate among those who received NA, but significant associations were not found $(\mathrm{OR}[95 \% \mathrm{CIs}]=0.79[0.58$, $1.09], I^{2}=32 \%, p$-value $\left.=0.16\right)$.

Comparison of the results of LAM, LdT, and TDF: Following the use of LAM, LdT, and TDF, the risk of HBsAg positivity of an infant at birth was reduced compared with the cases not using any NAs; however, only LdT showed a significant result (LAM: OR $\left[95 \%\right.$ CIs] $=0.63[0.38,1.06], I^{2}=$ $65 \%, p$-value $=0.05 ;$ LdT: OR $[95 \%$ CIs $]=0.37[0.24$, $0.57], I^{2}=67 \%, p$-value $<0.00001$; TDF: OR [95\% CIs] $=$ $0.53[0.21,1.33], I^{2}=60 \%, p$-value $=0.18$ ) (Fig. 2). The results from 20 studies, containing 4,041 infants, demonstrated a significant reduction of HBV DNA positivity at birth in babies of CHB-infected mothers, who were exposed to each of the NAs (LAM: OR [95\% CIs] $=0.15$ [0.06, 0.40], $I^{2}=$ $23 \%, p$-value $=0.0002 ;$ LdT: OR $[95 \% \mathrm{CIs}]=0.23[0.09$, $0.57], I^{2}=88 \%, p$-value $=0.001 ;$ TDF: OR $[95 \%$ CIs $]=$ $0.19[0.11,0.33], I^{2}=0 \%, p$-value <0.00001) (Fig. 3).

The analysis implies a higher efficacy of LdT in reducing the risk of MTCT (OR [95\% CIs] $=0.10$ [0.06, 0.15], $I^{2}=$ $16 \%, p$-value $<0.00001)$. The next most effective is TDF $\left(\mathrm{OR}[95 \% \mathrm{CIs}]=0.17[0.11,0.27], I^{2}=0 \%, p\right.$-value $<0.00001$ ), then LAM (OR [95\% CIs] $=0.24[0.14,0.39$, $I^{2}=11 \%, p$-value $<0.00001$ ) (Fig. 4). When associated with the risk of congenital malformation, none of the NAs was higher than the others. Indeed, despite their nonsignificant differences, each of these drugs may be a risk factor for congenital malformation development (LAM: OR [95\% CIs] $=$ $1.33[0.38,2.34], I^{2}=0 \%, p$-value $=0.58 ;$ LdT: OR $[95 \%$ CIs $]=1.70[0.57,5.03], I^{2}=0 \%, p$-value $=0.34 ;$ TDF: OR $[95 \%$ CIs $]=1.80[0.43,7.65], I^{2}=0 \%, p$-value $\left.=0.42\right)$.

\section{Maternal outcomes}

Comparison of antiviral therapy with no treatment: Among the selected studies, 10 (LAM $=3, \mathrm{LdT}=6$, TDF $=$ 1) evaluated the capacity of NAs therapy in terms of suppressing HBV DNA in mothers. The overall results showed encouraging results (OR $[95 \% \mathrm{CIs}]=25.53$ [8.59, 75.92], $I^{2}=62 \%$, $p$-value <0.00001) (Fig. 5A)). However, when $\mathrm{HBeAg}$ loss or seroconversion rates were analyzed, no significant differences were detected (HBeAg loss: OR [95\% CIs] = $2.90[1.58,5.34], I^{2}=58 \%, p$-value $=0.0006 ;$ HBeAg seroconversion: OR $\left[95 \%\right.$ CIs] $=2.68[1.59,4.52], I^{2}=53 \%$, $p$-value $=0.0002$ ). Moreover, no significant difference was found in the total results for the normalization of alanine aminotransferase levels (OR $[95 \%$ CIs $]=1.37[0.88,2.14], I^{2}=$ $95 \%, p$-value $=0.17)$. 
Sali S. et al: Treating chronic HBV during pregnancy

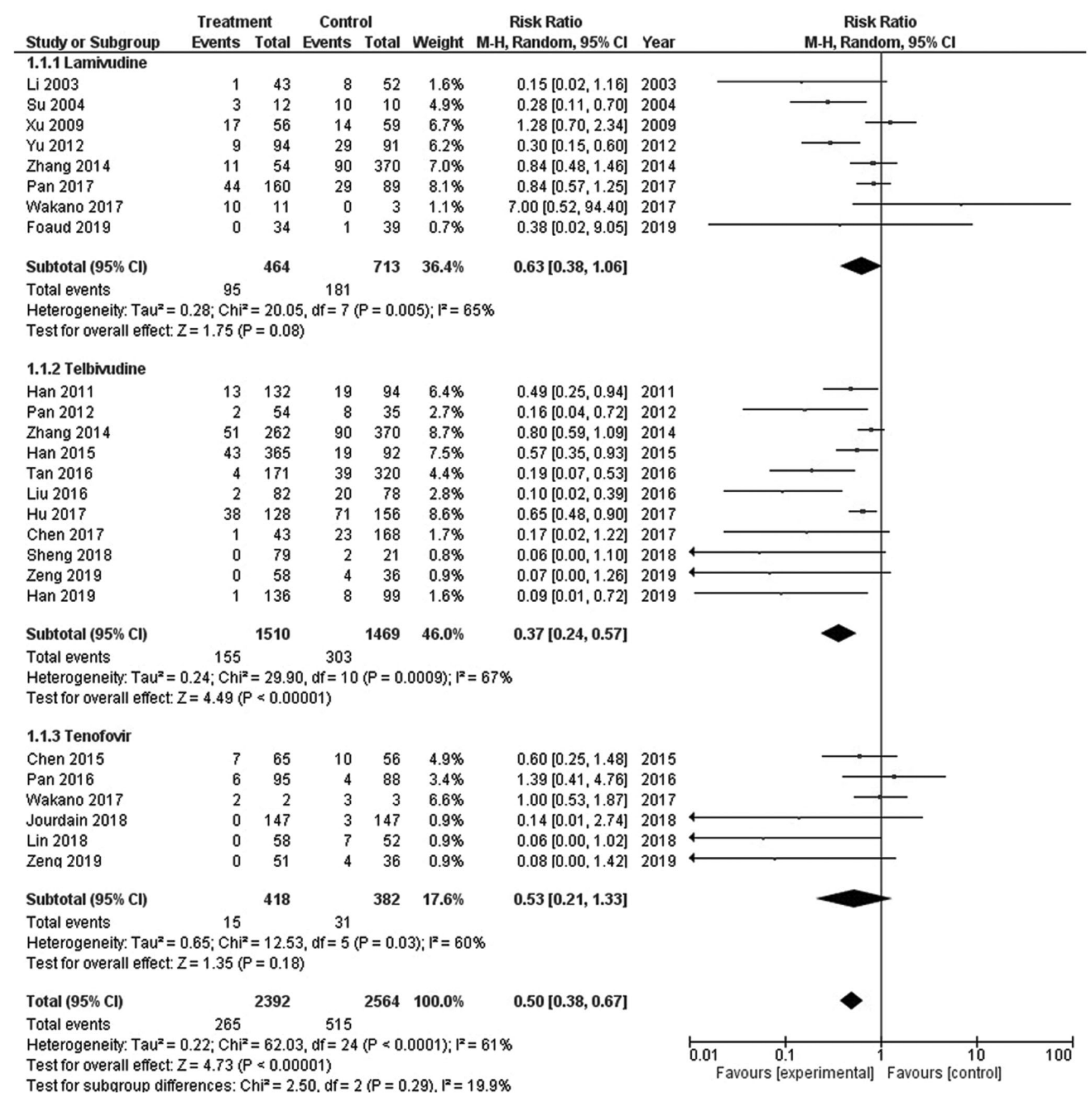

Fig. 2. Forest plots of infant HBSAg positivity at birth.

Abbreviation: $\mathrm{HBsAg}$, hepatitis B surface antigen.

For maternal side effects, two parameters were considered: CK elevation and postpartum hemorrhage. Interestingly, among the 1,619 mothers monitored from the NAs group for CK elevation, 22 of them showed a high level of CK. In contrast, none of the 994 mothers without NA therapy was reported. This could suggest NAs playing a role in CK elevation during the pregnancy (OR $[95 \% \mathrm{CIs}]=7.48$ $[2.41,23.24], I^{2}=0 \%, p$-value $\left.=0.0005\right)$ (Fig. 5B). However, no significant differences were found among the
NAs group and controls regarding postpartum hemorrhage (OR $[95 \%$ CIs $]=0.94[0.77,1.14], I^{2}=0 \%, p$-value $\left.=0.52\right)$.

Comparison of LAM, LdT, and TDF: The calculations showed that LdT probably had a greater capacity to suppress HBV DNA in pregnant women, compared with LAM (LAM: OR $[95 \%$ CIs $]=10.88[0.61,194.48], I^{2}=79 \%, p$-value $=$ 0.10 ; LdT: [95\% CIs] $=61.15$ [19.71, 189.74], $I^{2}=0 \%, p-$ value $<0.00001$ (Fig. 5A)). Moreover, LdT was the only NA which was capable to induce HBeAg loss and seroconversion 
Sali S. et al: Treating chronic HBV during pregnancy

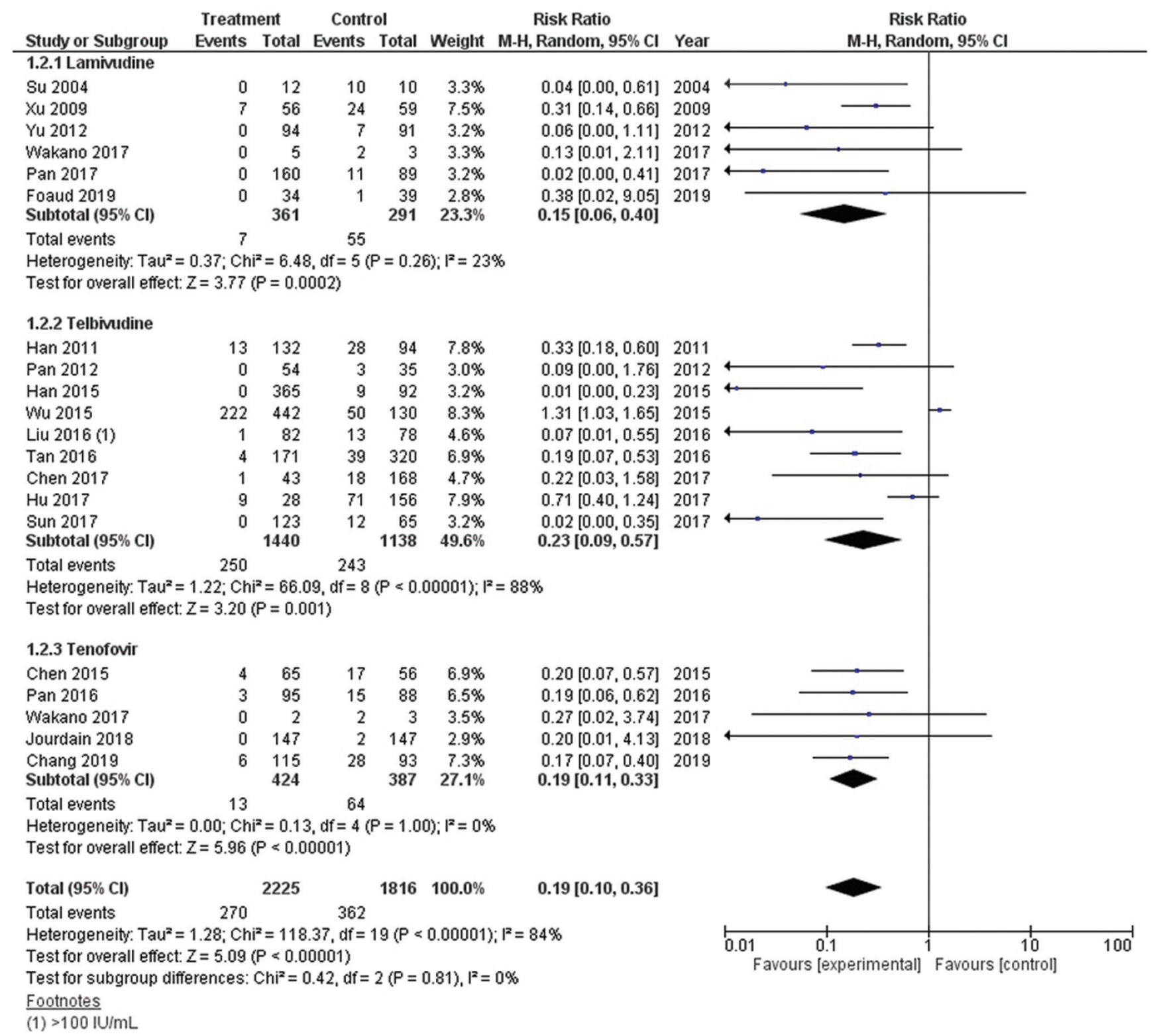

Fig. 3. Forest plots of infant HBV DNA positivity at birth.

Abbreviation: HBV, hepatitis B virus.

in a significant manner. $\mathrm{HBeAg}$ loss (LAM: OR [95\% CIs] = $1.20[0.62,2.33], I^{2}=$ not applicable, $p$-value $=0.59 ;$ LdT: OR $[95 \%$ CIs $]=12.14[2.17,67.92], I^{2}=0 \%, p$-value $=$ 0.004 ; TDF: OR $\left[95 \%\right.$ CIs] $=3.26[0.60,17.73], I^{2}=61 \%$, $p$-value $=0.17$ ) HBeAg seroconversion (LAM: OR [95\% CIs] $=$ $1.05[0.54,2.02], I^{2}=0 \%, p$-value $=0.89$; LdT: OR $[95 \%$ CIs $]=8.93[2.86,27.90], I^{2}=7 \%, p$-value $=0.0002 ;$ TDF: OR $[95 \%$ CIs $]=1.20[0.30,4.85], I^{2}=61 \%, p$-value $\left.=0.80\right)$.

Interestingly, the LdT groups also led to significant normalizations of alanine aminotransferase levels, as compared with off-therapy controls (OR [95\% CIs] $=1.49[1.30,1.72], I^{2}=$ $0 \%, p$-value $<0.00001$ ), but not LAM (OR [95\% CIs] $=2.47$ $[0.27,22.52], I^{2}=97 \%, p$-value $\left.=0.42\right)$. However, because of the low number of mothers included in the TDF group, as compared to the LdT group, these results might be revised in future analysis.

\section{Publication bias}

In order to evaluate publication bias in the studies included, a funnel plot was used. The shape of these plots for each analysis suggests no evidence of publication bias among the studies. As an example, the funnel plot for MTCT is shown in Fig. 6 .

\section{Discussion}

The rate of new HBV infections has declined by approximately $82 \%$ since $1991 .{ }^{37}$ However, women of childbearing age with 
Sali S. et al: Treating chronic HBV during pregnancy

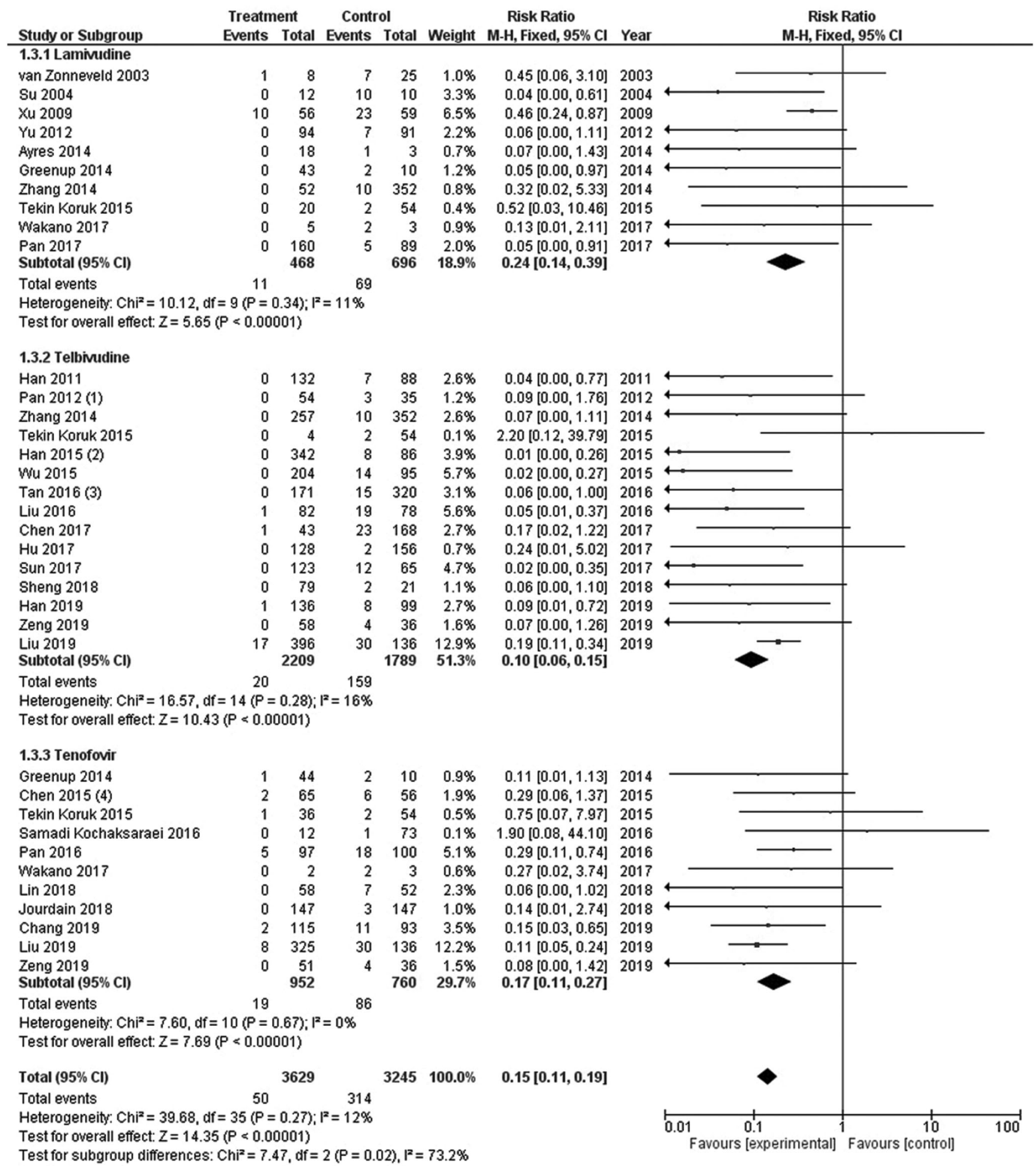
(1) Prior to delivery
(2) At age of 12 months
(3) positive for HBsAg or HBV DNA
(4) At 12 months of age

Fig. 4. Forest plots of mother-to-child transmission of HBV infection after 6-12 months.

Abbreviation: HBV, hepatitis B virus. 
Sali S. et al: Treating chronic HBV during pregnancy

(A)

Treatment Control

Risk Ratio

Risk Ratio

Study or Subgroup

Events Total Events Total Weight M-H, Random, $95 \% \mathrm{Cl}$ Year

NI 2005

Nl 2005
Yu 2012

Pan 2017

Subtotal $(95 \% \mathrm{Cl})$

Total events

$\begin{array}{rrrrrrr}5 & 29 & 3 & 29 & 14.7 \% & 1.67[0.44,6.34] & 2005 \\ 29 & 94 & 0 & 91 & 8.5 \% & 57.14[3.54,921.41] & 2012\end{array}$

$\begin{array}{llllrrrr} & 20 & 160 & 0 & 89 & 8.4 \% & 22.92[1.40,374.47] & 2017 \\ & 283 & & 209 & 31.6 \% & \mathbf{1 0 . 8 8}[\mathbf{0 . 6 1}, \mathbf{1 9 4 . 4 8 ]}\end{array}$

Heterogeneity: $\mathrm{Tau}^{2}=5.08 ; \mathrm{Chi}^{2}=9.67, \mathrm{df}=2(P=0.008) ; \mathrm{I}^{2}=79 \%$

Test for overall effect: $Z=1.62(P=0.10)$

2.6.2 Telbimudine

Han 2011

Pan 2012

Han 2015 (1)

Wu 2015

Yi 2017

Han 2019

Subtotal $(95 \%$ Cl)

Total events

Heterogeneity: Tau $^{2}=0.00 ; \mathrm{Chi}^{2}=0.26, \mathrm{df}=5(P=1.00) ; \mathrm{I}^{2}=0 \%$

Test for overall effect: $Z=7.12(P<0.00001)$

\subsubsection{Tenofovir}

$\begin{array}{llllllll}\begin{array}{l}\text { 2.6.3 Tenofovir } \\ \text { Chen } 2017\end{array} & 29 & 43 & 8 & 168 & 17.5 \% & 14.16[6.98,28.73] & 2017\end{array}$

Subtotal ( $95 \%$

Total events

$\begin{array}{lllllll}44 & 135 & 0 & 94 & 8.5 \% & 62.17[3.88,997.10] 2011\end{array}$

$\begin{array}{lrlllll}28 & 53 & 0 & 35 & 8.5 \% & 38.00[2.40,602.82] & 2012\end{array}$

$\begin{array}{lllllll}96 & 362 & 0 & 92 & 8.5 \% & 49.45[3.10,788.80] & 2015\end{array}$

$\begin{array}{lllllll}40 & 172 & 0 & 154 & 8.5 \% & 72.57[4.50,1170.29] & 2015\end{array}$

$\begin{array}{lllllll}39 & 220 & 0 & 176 & 8.5 \% & 63.27[3.92,1022.20] & 2017\end{array}$

$\begin{array}{lllllll}66 & 139 & 0 & 102 & 8.5 \% & 97.85[6.13,1562.41] & 2019\end{array}$

Heterogeneity: Not applicable

Test for overall effect: $Z=7.34(P<0.00001)$

$\begin{array}{lllllll}\text { Total }(95 \% \mathrm{Cl}) & & 1407 & 1030 & 100.0 \% & 25.53[8.59,75.92]\end{array}$

$\begin{array}{lcl}\text { Total events } & 396 & 11 \\ \text { Heterogeneity: } \text { Tau }^{2}=1.64 ; \mathrm{Chi}^{2}=23.87, \mathrm{df}=9(\mathrm{P}=0.005) ; \mathrm{l}^{2}=62 \%\end{array}$

Heterogeneity: $T_{a} u^{2}=1.64 ; \mathrm{Chi}^{2}=23.87, \mathrm{df}=9($
Test for overall effect: $Z=5.83(\mathrm{P}<0.00001)$

Test for subgroup differences: $\mathrm{Chi}^{2}=4.81, \mathrm{df}=2(\mathrm{P}=0.09), \mathrm{I}^{2}=58.4 \%$

$\begin{array}{ll}14.16[6.98,28.73] & 2017 \\ 14.16[6.98,28.73] & \end{array}$

Footnotes

(1) $<500$ copies $/ \mathrm{mL}$

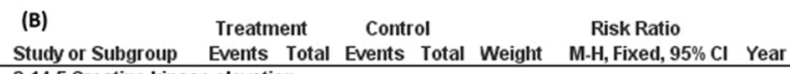
2.14.5 Creatine kinase elevation

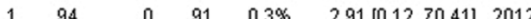

Celen 2013

Zhang 2014

Wu 2015

Pan 2016

Liu 2019

Han 2019

Subtotal $(95 \% \mathrm{Cl})$

Total events

Heterogeneity. $\mathrm{Chi}^{2}=2.97, \mathrm{df}=5(\mathrm{P}=0.70) ; \mathrm{I}^{2}=0 \%$

Test for overall effect: $Z=3.48(P=0.0005)$

2.14.6 Postpartum hemorrhage

\begin{tabular}{lllllll} 
Yu 2011 & 26 & 40 & 21 & 30 & $16.5 \%$ & 0.9310 .07 \\
\hline & 33 & 94 & 36 & 91 & $25.2 \%$ & 0.89
\end{tabular}

Yu 2012

Greenup 2014 (1)

Chen 2015 (2)

Tan 2016

Liu 2016

Pan 2016

Yi 2017

Hu 2017

Sun 2017

Pan 2017

Lin 2018

Liu 2019

Zeng 2019

Subtotal $(95 \% \mathrm{Cl})$

Total events

Heterogeneity: $\mathrm{Chi}^{2}=5.34, \mathrm{df}=11(\mathrm{P}=0.91) ; \mathrm{I}^{2}=0 \%$

Test for overall effect: $Z=0.64(P=0.52)$

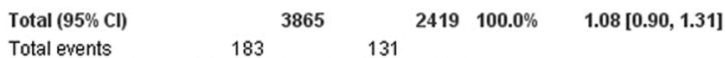

Heterogeneity: $\mathrm{Chi}^{2}=18.32, \mathrm{df}=17(\mathrm{P}=0.37) ; \mathrm{I}^{2}=7 \%$

Test for overall effect: $Z=0.83(P=0.41)$

Test for subgroup differences: $\mathrm{Chi}^{2}=12.52, \mathrm{df}=1(P=0.0004), \mathrm{I}^{2}=92.0 \%$

$0.89[0.61,1.29] 2012$

$0.89[0.61,1.29] 2012$

$1.08[0.68,1.69] 2015$

$1.04[0.35,3.05] 2016$

$\begin{array}{rr}1.04[0.35,3.05] & 2016 \\ \text { Not estimable } 2016\end{array}$ $1.03[0.27,4.01] 2016$ $0.71[0.36,1.38] 2017$ $0.96[0.26,3.51] 2017$ $0.88[0.46,1.69] 2017$ $1.95[0.41,9.17] 2017$ $\begin{array}{ll}1.95[0.41,9.17] & 2017 \\ \text { Not estimable } 2018\end{array}$ $\begin{array}{rr}\text { Not estimable } 2018 \\ 0.19[0.01,3.00] & 2019\end{array}$ $0.19[0.01,3.00] 2019$ $0.94[0.77,1.14]$

Footnotes

(1) $\mathrm{TDF}=58, \mathrm{LAM}=53$

(2) At 12 months of age

M-H, Random, $95 \% \mathrm{CI}$

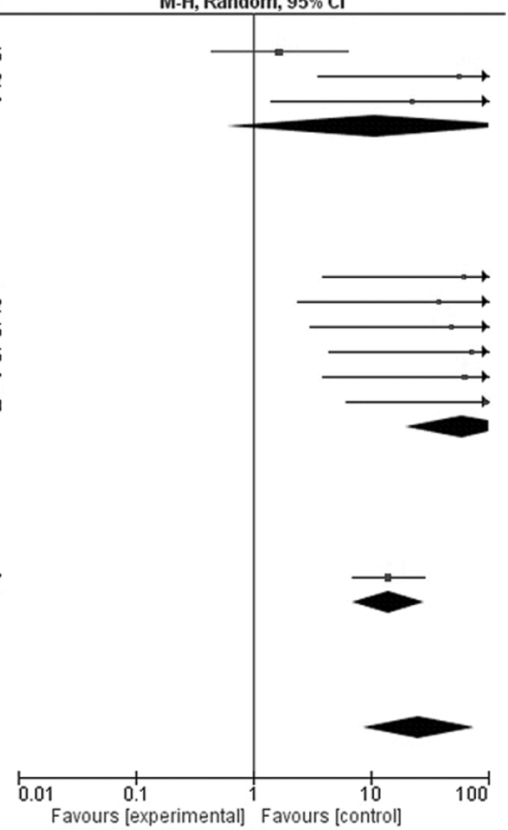

Favours [experimental] Favours [contro] 


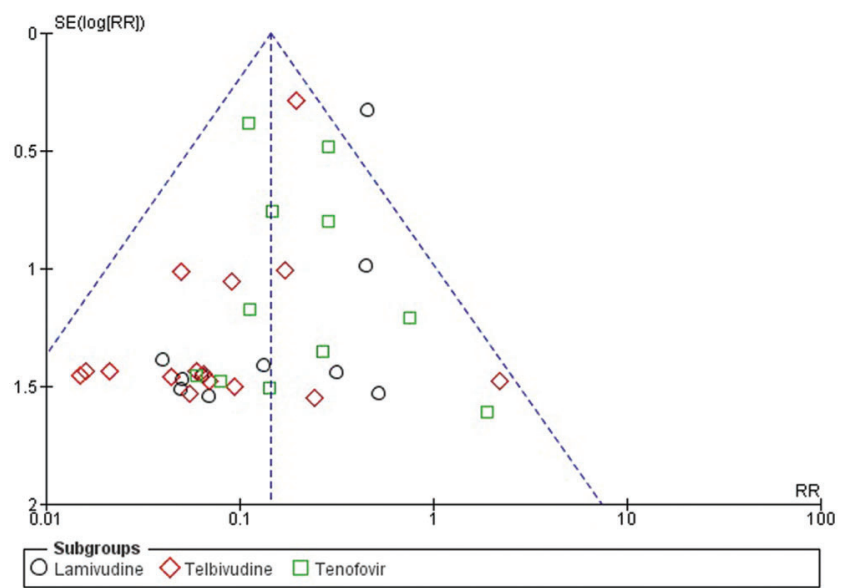

Fig. 6. Funnel plot analysis to examine publication bias for mother-tochild transmission.

$\mathrm{CHB}$ infections remain an important source of the continued spread of HBV. Hence, it is critical to prevent the maternal vertical transmission of HBV to reduce the overall number of $\mathrm{CHB}$ patients. Pregnant women are vulnerable to several treatments and diseases. In the case of HBV and its associated therapeutic options, several important points should be considered. The capacity of medications to prevent MTCT as well as the safety of both infant and mother are the uppermost considerations. In addition to the comparison of these factors between treatment groups and controls, it is important to identify the drugs with the highest efficacy and the safest profiles for both mother and infant. As mentioned, regardless of drug type, NAs have been shown to be beneficial for pregnant women, while some of their side effects influence both infant and mothers.

The results from the studies analyzed in this study showed that the prevalence of positive HBsAg and/or HBV DNA is significantly lower in a newborn infant from $\mathrm{CHB}$ mothers who received antiviral therapy in the second or third trimester. Moreover, they have a greater chance to be non-HBV carriers at 6 months. There are several studies that have reported lower immunoprophylaxis failure as the results of antiviral therapy during pregnancy. Some evidence is also available that implies the roles of antiviral therapy during pregnancy in preventing several other undesirable fetal outcomes, including low birth weight, premature birth, abortion, and death. Mothers may also have greater chances for the suppression of HBV DNA, HBeAg loss/seroconversion, and alanine aminotransferase normalization.

However, there are some risks that could threaten both infants and mothers. One of the most critical ones is the relatively increased but nonsignificant risk of congenital malformations as a result of exposure to NAs. Additionally, mothers exposed to NAs may experience more severe side effects, such as CK elevation. Recently, Brown et al. ${ }^{12}$ assessed the risk of $\mathrm{CK}$ elevation as a result of NA therapy. In contrast to the current study, they could not find any significant association between the CK elevation and NA therapy. Hyun et al. ${ }^{13}$ also suggested a possible role of TDF therapy in CK elevation in pregnant women but did not find any statistically significant association. The difference in the results might be explained by the attention placed on CK during recent years, or increases in the number of studies analyzed. Selected other outcomes reported in certain published metaanalyses are displayed in Table 2.

According to the European Association for the Study of the Liver recommendations for pregnant women with CHB: (1) those with positive HBsAg should be screened in the first trimester of pregnancy (Evidence level 1, the grade of recommendation 1); (2) in a CHB-infected woman of childbearing age without advanced fibrosis who plans a pregnancy in the future, delaying therapy until the child is born was recommended (Evidence level II-2, the grade of recommendation 1); (3) for pregnant women with $\mathrm{CHB}$ and advanced fibrosis or cirrhosis, therapy with TDF is recommended (Evidence level II-2, the grade of recommendation 1); and (4) continuing TDF and switching to TDF in those under treatment with other NAs was also recommended (Evidence level II-2, the grade of recommendation 1 ; these are consistent with TDF and LdT being in a safer category than LAM (Federal Drug Administration Pregnancy Category B vs. C), and a higher barrier to resistance in TDF than LdT); (5) in pregnant women with either HBV DNA $>200,000 \mathrm{IU} / \mathrm{mL}$ or HBsAg levels $>4 \log \mathrm{IU} / \mathrm{mL}$, starting antiviral prophylaxis with TDF at week 24-28 of gestation and continuing for up to 12 weeks after delivery was recommended (Evidence level 1, the grade of recommendation 1 ). The recommendation to continue for up to 12 weeks might be due to high risk of postpartum alanine aminotransferase level elevation in $\mathrm{CHB}$ patients, especially mothers with elevated alanine aminotransferase or HBV DNA levels $\geq 5 \log _{10} \mathrm{IU} / \mathrm{mL}$ at delivery. ${ }^{38}$

Compared with other NAs, the number of TDF studies was lower. This may affect the accuracy of analyses associated with this type of drug. During the analysis of factors that contain a low number of studies, NA types were not distinguished. However, those with distinguished results support the high efficacy of LdT. Indeed, in almost all the analyses, LdT was more effective in the reduction of undesirable outcomes associated with both infants and mothers but was not an entirely safe drug. ${ }^{39}$ Drug-resistance is one of the most challenging issues related to the treatment of pregnant women with CHB. Interestingly, using LdT in such patients rarely could lead to LdT-related resistance. In the reviewed studies, only Li et al. ${ }^{18}$ reported an HBV M204I drug resistance mutation at the 40th week of treatment in one patient. However, the others did not report any LdT-resistance development during the study periods. $4,7-9,19,20$ This could be explained by the fact that short-term use of LdT is not enough to induce obvious resistance. ${ }^{9}$ Analyzing the risk of congenital malformation, no significant difference was found, while neither LAM, LdT, nor TDF, could be presented as an utterly safe drug. Table 2 summarizes the results of previous meta-analyses regarding the efficacy and safety of treatments for CHB during pregnancy.

In spite of the multiple analyses conducted, this study has some limitations, which may affect the selection of drugs for an individual. First, it does not cover treatment and safety predictive factors, such as positivity for $\mathrm{HBsAg}$, baseline levels of HBV DNA, duration of disease, HBV genotypes, and so on. Second, drug resistance - a critical factor for drug choice - was not considered. Third, only journal articles in English language that were indexed in PubMed and Scopus were included in the study. The lack of analysis regarding NAs treatment duration is another limitation of the current study.

In conclusion, it has been shown that NAs therapy is essential for pregnant women with $\mathrm{CHB}$ to prevent the 
Sali S. et al: Treating chronic HBV during pregnancy

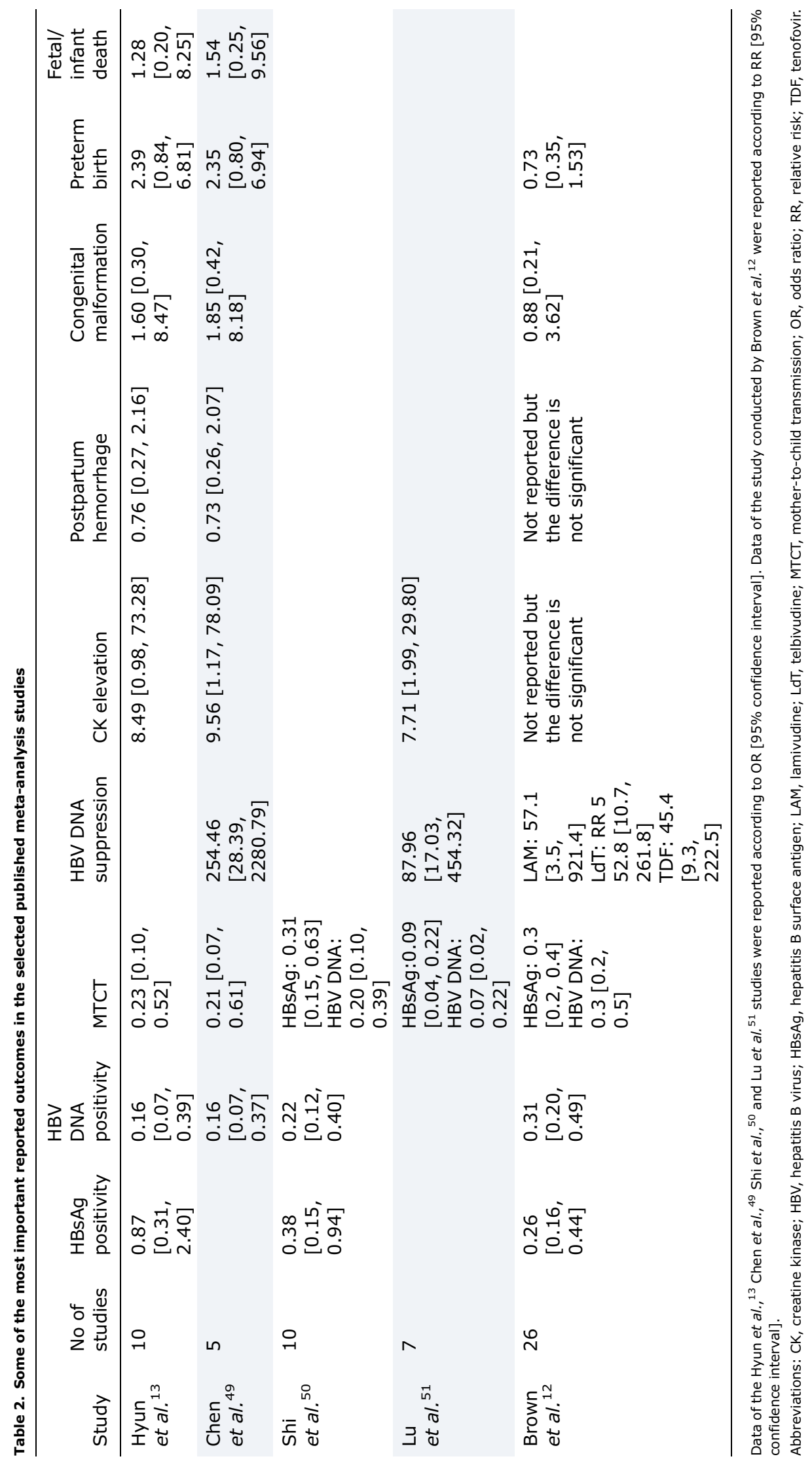


MTCT of HBV as well as to decrease various undesirable infant outcomes. However, mothers should be warned of the possible risk of elevated CK. Based on the findings, LdT therapy is more effective than others, while more studies on TDF, which has a high barrier to resistance, are needed to clarify TDF efficacy and safety.

\section{Conflict of interest}

The authors have no conflict of interests related to this publication.

\section{Author contributions}

Conceptualized the study (ST, SS), performed the literature search and data analysis (AM, MGA, SEB, MA, HSZ, SS), drafted the manuscript (ST), critically revised the work (SS, $M D, S T)$.

\section{References}

[1] World Health Organization. Guidance on prevention of viral hepatitis B and C among people who inject drugs. 2012. Available from: https://apps.who. int/iris/bitstream/handle/10665/75357/9789241504041_eng.pdf;jsessionid $=62031292140$ D0CB41D0AFF31837AC872? sequence $=1$. Accessed July 2012.

[2] Das S, Ramakrishnan K, Behera SK, Ganesapandian M, Xavier AS, Selvarajan S. Hepatitis B vaccine and immunoglobulin: Key concepts. J Clin Transl Hepatol 2019;7:165-171. doi: 10.14218/JCTH.2018.00037.

[3] Hu P, Shang J, Zhang W, Gong G, Li Y, Chen X, et al. HBsAg loss with peginterferon alfa-2a in hepatitis $B$ patients with partial response to nucleos $(t)$ ide analog: New switch study. J Clin Transl Hepatol 2018;6:25-34. doi: 10. 14218/JCTH.2017.00072.

[4] Pan CQ, Han GR, Jiang HX, Zhao W, Cao MK, Wang CM, et al. Telbivudine prevents vertical transmission from $\mathrm{HBeAg}$-positive women with chronic hepatitis B. Clin Gastroenterol Hepatol 2012;10:520-526. doi: 10.1016/j. cgh.2012.01.019.

[5] Xu WM, Cui YT, Wang L, Yang H, Liang ZQ, Li XM, et al. Lamivudine in late pregnancy to prevent perinatal transmission of hepatitis $B$ virus infection: a multicentre, randomized, double-blind, placebo-controlled study. J Viral Hepat 2009;16:94-103. doi: 10.1111/j.1365-2893.2008.01056.x.

[6] Han GR, Cao MK, Zhao W, Jiang HX, Wang CM, Bai SF, et al. A prospective and open-label study for the efficacy and safety of telbivudine in pregnancy for the prevention of perinatal transmission of hepatitis $B$ virus infection. J Hepatol 2011;55:1215-1221. doi: 10.1016/j.jhep.2011.02.032.

[7] Zhang H, Pan CQ, Pang Q, Tian R, Yan M, Liu X. Telbivudine or lamivudine use in late pregnancy safely reduces perinatal transmission of hepatitis $B$ virus in real-life practice. Hepatology 2014;60:468-476. doi: 10.1002/hep.27034.

[8] Han GR, Jiang HX, Yue X, Ding Y, Wang CM, Wang GJ, et al. Efficacy and safety of telbivudine treatment: an open-label, prospective study in pregnant women for the prevention of perinatal transmission of hepatitis B virus infection. J Viral Hepat 2015;22:754-762. doi: 10.1111/jvh.12379.

[9] Wu Q, Huang H, Sun X, Pan M, He Y, Tan S, et al. Telbivudine prevents vertical transmission of hepatitis $B$ virus from women with high viral loads: a prospective long-term study. Clin Gastroenterol Hepatol 2015;13:1170-1176. doi: $10.1016 / j . c g h .2014 .08 .043$.

[10] Brown RS Jr, Verna EC, Pereira MR, Tilson HH, Aguilar C, Leu CS, et al. Hepatitis $B$ virus and human immunodeficiency virus drugs in pregnancy: findings from the Antiretroviral Pregnancy Registry. J Hepatol 2012;57: 953-959. doi: 10.1016/j.jhep.2012.06.031.

[11] Nachega JB, Uthman OA, Mofenson LM, Anderson JR, Kanters S, Renaud F, et al. Safety of tenofovir disoproxil fumarate-based antiretroviral therapy regimens in pregnancy for HIV-infected women and their infants: A systematic review and meta-analysis. J Acquir Immune Defic Syndr 2017;76:1-12. doi: 10.1097/QAI.0000000000001359.

[12] Brown RS Jr, McMahon BJ, Lok AS, Wong JB, Ahmed AT, Mouchli MA, et al. Antiviral therapy in chronic hepatitis $B$ viral infection during pregnancy: $A$ systematic review and meta-analysis. Hepatology 2016;63:319-333. doi: 10.1002/hep. 28302.

[13] Hyun MH, Lee YS, Kim JH, Je JH, Yoo YJ, Yeon JE, et al. Systematic review with meta-analysis: the efficacy and safety of tenofovir to prevent motherto-child transmission of hepatitis B virus. Aliment Pharmacol Ther 2017;45: 1493-1505. doi: 10.1111/apt.14068.
[14] Mantel N, Haenszel W. Statistical aspects of the analysis of data from retrospective studies of disease. J Natl Cancer Inst 1959;22:719-748.

[15] Nguyen V, Tan PK, Greenup AJ, Glass A, Davison S, Samarasinghe D, et al. Anti-viral therapy for prevention of perinatal HBV transmission: extending therapy beyond birth does not protect against post-partum flare. Aliment Pharmacol Ther 2014;39:1225-1234. doi: 10.1111/apt.12726.

[16] Tekin Koruk S, Batirel A, Kose S, Cetin Akhan S, Aygen B, Tulek N, et al. Evaluation of hepatitis $B$ virus transmission and antiviral therapy among hepatitis B surface antigen-positive pregnant women. J Obstet Gynaecol Res 2015;41:1870-1876. doi: 10.1111/jog.12821.

[17] Tan Z, Yin Y, Zhou J, Wu L, Xu C, Hou H. Telbivudine treatment of hepatitis B virus-infected pregnant women at different gestational stages for the prevention of mother-to-child transmission: Outcomes of telbivudine treatment during pregnancy. Medicine (Baltimore) 2016;95:e4847. doi: 10.1097/MD. 0000000000004847.

[18] Liu Y, Wang M, Yao S, Yuan J, Lu J, Li H, et al. Efficacy and safety of telbivudine in different trimesters of pregnancy with high viremia for interrupting perinatal transmission of hepatitis B virus. Hepatol Res 2016;46:E181E188. doi: 10.1111/hepr.12525.

[19] Hu Y, Xu C, Xu B, Hu L, Liu Q, Chen J, et al. Safety and efficacy of telbivudine in late pregnancy to prevent mother-to-child transmission of hepatitis $B$ virus: A multicenter prospective cohort study. J Viral Hepat 2018;25:429437. doi: $10.1111 /$ jvh. 12834

[20] Sun W, Zhao S, Ma L, Hao A, Zhao B, Zhou L, et al. Telbivudine treatment started in early and middle pregnancy completely blocks HBV vertical transmission. BMC Gastroenterol 2017;17:51. doi: 10.1186/s12876-017-0608-7.

[21] Yi W, Li MH, Xie Y, Wu J, Hu YH, Zhang D, et al. Prospective cohort study on the efficacy and safety of telbivudine used throughout pregnancy in blocking mother-to-child transmission of hepatitis B virus. J Viral Hepat 2017;24 Suppl 1:49-56. doi: 10.1111/jvh.12788.

[22] Chen ZX, Gu GF, Bian ZL, Cai WH, Shen Y, Hao YL, et al. Clinical course and perinatal transmission of chronic hepatitis $B$ during pregnancy: A real-world prospective cohort study. J Infect 2017;75:146-154. doi: 10.1016/j.jinf. 2017.05.012.

[23] Han LF, Zheng JM, Zheng LQ, Gao HB, Chen LX, Xu QL, et al. Telbivudine can safely reduce mother-to-child transmission in chronic hepatitis $B$ women after 12 weeks of gestation. BMC Infect Dis 2019;19:614. doi: 10 . 1186/s12879-019-4250-6.

[24] Liu J, Wang J, Yan T, Du D, Qi C, Cao F, et al. Efficacy and safety of telbivudine and tenofovir disoproxil fumarate in preventing hepatitis $B$ vertical transmission: A real-life practice. J Viral Hepat 2019. doi: 10.1111/jvh.13156.

[25] Sheng Q, Ding Y, Li B, Han C, Li Y, Zhang C, et al. Efficacy and safety of nucleos $(\mathrm{t})$ ide analogues to prevent hepatitis $\mathrm{B}$ virus mother-to-child transmission in pregnant women with high viremia: real life practice from China. Int J Med Sci 2018;15:796-801. doi: 10.7150/ijms.25047.

[26] Zeng J, Zheng C, Li H. Effectiveness of tenofovir or telbivudine in preventing HBV vertical transmission for pregnancy. Medicine (Baltimore) 2019;98: e15092. doi: 10.1097/MD.0000000000015092.

[27] Celen MK, Mert D, Ay M, Dal T, Kaya S, Yildirim N, et al. Efficacy and safety of tenofovir disoproxil fumarate in pregnancy for the prevention of vertical transmission of HBV infection. World J Gastroenterol 2013;19:9377-9382. doi: $10.3748 /$ wjg.v19.i48.9377.

[28] Greenup AJ, Tan PK, Nguyen V, Glass A, Davison S, Chatterjee U, et al. Efficacy and safety of tenofovir disoproxil fumarate in pregnancy to prevent perinatal transmission of hepatitis B virus. J Hepatol 2014;61: 502-507. doi: 10.1016/j.jhep.2014.04.038.

[29] Pan CQ, Duan Z, Dai E, Zhang S, Han G, Wang Y, et al. Tenofovir to prevent hepatitis B transmission in mothers with high viral load. N Engl J Med 2016; 374:2324-2334. doi: 10.1056/NEJMoa1508660.

[30] Samadi Kochaksaraei G, Castillo E, Osman M, Simmonds K, Scott AN, Oshiomogho JI, et al. Clinical course of 161 untreated and tenofovirtreated chronic hepatitis B pregnant patients in a low hepatitis B virus endemic region. J Viral Hepat 2016;23:15-22. doi: 10.1111/jvh.12436.

[31] Wakano Y, Sugiura T, Endo T, Ito K, Suzuki M, Tajiri H, et al. Antiviral therapy for hepatitis B virus during second pregnancies. J Obstet Gynaecol Res 2018; 44:566-569. doi: 10.1111/jog.13540.

[32] Chen HL, Lee CN, Chang CH, Ni YH, Shyu MK, Chen SM, et al. Efficacy of maternal tenofovir disoproxil fumarate in interrupting mother-to-infant transmission of hepatitis B virus. Hepatology 2015;62:375-386. doi: 10. 1002/hep.27837.

[33] Chang KC, Chang MH, Lee CN, Chang CH, Wu JF, Ni YH, et al. Decreased neonatal hepatitis $\mathrm{B}$ virus (HBV) viremia by maternal tenofovir treatment predicts reduced chronic HBV infection in children born to highly viremic mothers. Aliment Pharmacol Ther 2019;50:306-316. doi: 10.1111/apt.15321.

[34] Jourdain G, Ngo-Giang-Huong N, Harrison L, Decker L, Khamduang W, Tierney C, et al. Tenofovir versus placebo to prevent perinatal transmission of hepatitis $\mathrm{B}$. N Engl J Med 2018;378:911-923. doi: 10.1056/NEJMoa1708131.

[35] Lin Y, Liu Y, Ding G, Touqui L, Wang W, Xu N, et al. Efficacy of tenofovir in preventing perinatal transmission of HBV infection in pregnant women with high viral loads. Sci Rep 2018;8:15514. doi: 10.1038/s41598-018-33833-w. 
[36] Su GG, Pan KH, Zhao NF, Fang SH, Yang DH, Zhou Y. Efficacy and safety of lamivudine treatment for chronic hepatitis B in pregnancy. World J Gastroenterol 2004;10:910-912. doi: 10.3748/wjg.v10.i6.910.

[37] Daniels D, Grytdal S, Wasley A. Surveillance for acute viral hepatitis - United States, 2007. MMWR Surveill Summ 2009;58:1-27.

[38] Yi W, Pan CQ, Li MH, Wan G, Lv YW, Liu M, et al. The characteristics and predictors of postpartum hepatitis flares in women with chronic hepatitis $\mathrm{B}$. Am J Gastroenterol 2018:113:686-693 doi: 10.1038/s41395-018-0010-2.

[39] Tavakolpour S, Darvishi M, Mirsafaei HS, Ghasemiadl M. Nucleoside/nucleotide analogues in the treatment of chronic hepatitis $B$ infection during pregnancy: a systematic review. Infect Dis (Lond) 2018;50:95-106. doi: 10 . 1080/23744235.2017.1384957.

[40] Li XM, Yang YB, Hou HY, Shi Z], Shen HM, Teng BQ, et al. Interruption of HBV intrauterine transmission: a clinical study. World J Gastroenterol 2003;9: 1501-1503. doi: 10.3748/wjg.v9.i7.1501.

[41] van Zonneveld M, van Nunen AB, Niesters HG, de Man RA, Schalm SW, Janssen $\mathrm{HL}$. Lamivudine treatment during pregnancy to prevent perinatal transmission of hepatitis B virus infection. J Viral Hepat 2003;10:294-297. doi: $10.1046 / j .1365-2893.2003 .00440 . x$.

[42] $\mathrm{Ni} Y \mathrm{H}$, Huang FC, Wu TC, Kong MS, Jeng YM, Chen PJ, et al. Lamivudine treatment in maternally transmitted chronic hepatitis $B$ virus infection patients. Pediatr Int 2005;47:372-377. doi: 10.1111/j.1442-200x.2005. 02101.x.

[43] Yu M, Ji Y, Jiang $H$, Ju L, Wu K, Kan N. Efficacy of peripartum antiviral treatment for hepatic failure due to hepatitis B virus. Int J Gynaecol Obstet 2011; 114:33-36. doi: 10.1016/j.ijgo.2011.03.004.

[44] Yu $M$, Jiang $Q$, Ji $Y$, Jiang $H$, Wu $K$, Ju $L$, et al. The efficacy and safety of antiviral therapy with lamivudine to stop the vertical transmission of hepatitis B virus. Eur J Clin Microbiol Infect Dis 2012;31:2211-2218. doi: 10.1007/s10096-012-1557-2.

[45] Ayres A, Yuen L, Jackson KM, Manoharan S, Glass A, Maley M, et al. Short duration of lamivudine for the prevention of hepatitis $B$ virus transmission in pregnancy: lack of potency and selection of resistance mutations. J Viral Hepat 2014;21:809-817. doi: 10.1111/jvh.12212.

[46] Pan CQ, Yi W, Liu M, Wan G, Hu YH, Zhou MF. Lamivudine therapy during the second vs the third trimester for preventing transmission of chronic hepatitis $B$. J Viral Hepat 2017;24:246-252. doi: 10.1111/jvh.12640.

[47] Sheng QJ, Wang SJ, Wu YY, Dou XG, Ding Y. Hepatitis B virus serosurvey and awareness of mother-to-child transmission among pregnant women in Shenyang, China: An observational study. Medicine (Baltimore) 2018;97: e10931. doi: 10.1097/MD.0000000000010931.

[48] Foaud HM, Maklad S, Gmal El Din A, Mahmoud F. Lamivudine use in pregnant $\mathrm{HBsAg-females} \mathrm{effectively} \mathrm{reduces} \mathrm{maternal} \mathrm{viremia.} \mathrm{Arab} \mathrm{J} \mathrm{Gastroenterol}$ 2019;20:8-13. doi: 10.1016/j.ajg.2019.02.003.

[49] Chen JZ, Liao ZW, Huang FL, Su RK, Wang WB, Cheng XY, et al. Efficacy and safety of tenofovir disoproxil fumarate in preventing vertical transmission of hepatitis B in pregnancies with high viral load. Sci Rep 2017;7:4132. doi: 10. 1038/s41598-017-04479-x.

[50] Shi Z, Yang Y, Ma L, Li X, Schreiber A. Lamivudine in late pregnancy to interrupt in utero transmission of hepatitis $B$ virus: a systematic review and meta-analysis. Obstet Gynecol 2010;116:147-159. doi: 10. 1097/AOG.0b013e3181e45951.

[51] Lu YP, Liang X], Xiao XM, Huang SM, Liu ZW, Li J, et al. Telbivudine during the second and third trimester of pregnancy interrupts HBV intrauterine transmission: a systematic review and meta-analysis. Clin Lab 2014;60:571586. doi: 10.7754/clin.lab.2013.130408. 